\title{
Impact of the COVID-19 Pandemic on the Public's Interest in Gastrointestinal Related Disease
}

\author{
Michael Yan ( $\nabla$ michaelyanusa@gmail.com ) \\ Westchester Medical Center https://orcid.org/0000-0002-7556-3794 \\ Haig Pakhchanian \\ GW Hospital: The George Washington University Hospital \\ Rahul Raiker \\ West Virginia University Health Sciences Center \\ Osama Boustany \\ West Virginia University - Health Sciences Campus: West Virginia University Health Sciences Center \\ Ahmad Khan \\ UH Cleveland Medical Center \\ Shailendra Singh \\ West Virginia University - Health Sciences Campus: West Virginia University Health Sciences Center
}

\section{Research Article}

Keywords: Infodemiology, Health services, Gastrointestinal, COVID-19, Google Trends, Epidemiology

Posted Date: February 24th, 2022

DOI: https://doi.org/10.21203/rs.3.rs-1312751/v1

License: @ (i) This work is licensed under a Creative Commons Attribution 4.0 International License. Read Full License 


\section{Abstract \\ Background}

There has been a significant disparity in familiarity regarding the public interest in gastroenterology terminologies during the COVID-19 pandemic. This study aimed to understand how the public's view on gastrointestinal topics changed throughout the pandemic.

\section{Methods}

A comparative analysis of American Google search volume trends of gastrointestinal terminology in the first six seasons (March 1, 2018, to August 31, 2021) of the COVID-19 pandemic was used as the basis of this infodemiology study. Then, data were compared to a similar time frame (March 2018-February 2020) to determine how trends in the patient-seeking behavior of gastrointestinal terminology changed during the pandemic.

\section{Results}

The analysis discovered a substantial decrease in search volumes of gastrointestinal topics, more significantly in the first pandemic months. As the months progressed, search volumes appeared to trend toward pre-pandemic years in terms of public interest and, in the case of procedures, surpassed pre-pandemic interest levels.

\section{Conclusion}

The public's decreased interest in gastrointestinal topics at the beginning of the COVID-19 pandemic may have adverse effects on the health care maintenance of patients who could have had a positive outcome in their gastrointestinal health with proper monitoring. Although gastrointestinal internet searches increased toward pre-pandemic levels as the seasons progressed, further research is needed to determine the long-term impact of decreased public interest.

\section{Introduction}

The Coronavirus 2019 disease (COVID-19) pandemic has imposed unprecedented changes to people's daily lives. Since national lockdowns were issue in March 2020, an added emphasis has been placed on the COVID-19-related health issues. During the pandemic, the public has experienced a new way of living involving COVID-19 prevention measures, treatment, testing procedures, new work protocols, and vaccination efforts. While these abrupt changes have had a profound impact on contracting the disease, these changes compounded by new healthcare administration protocols may have impacted the public's interest in non-COVID-19-related health issues.

Google Trends is an internet tool used to determine geographical and time-based Google search trends for keywords (Eysenbach 2006). It has been utilized as a valuable resource in determining public interest among different medical fields such as dermatology (Kutlu 2020), pediatric neurosurgery (Güdük 2021), musculoskeletal disease (Kardeş 2021), and mental health (Becerra-García 2021).

Unfortunately, there is limited information on patient search interest in gastrointestinal disease during the COVID-19 pandemic. As there have been an increase in alcohol consumption and adoption of unhealthy lifestyles due to lockdowns during the pandemic, gastrointestinal health should be emphasized especially in these vulnerable populations (Pakhchanian 2021). Therefore, the aim of this study is to utilize Google Trends to evaluate the American public interest in gastrointestinal disease during the COVID-19 pandemic.

\section{Materials And Methods}

Relative search volume (RSV) was used to evaluate the Google search frequency for commonly used gastrointestinal symptom, test, and procedure terms (Table 1). RSV is a normalized value on a scale from zero to one hundred where the value of one hundred represents the highest search volume over a selected timeframe, while a value of zero represents the least absolute search volume. 


\begin{tabular}{|c|c|c|c|c|c|c|c|c|c|c|c|}
\hline \multirow[b]{2}{*}{ Disease Terms } & \multicolumn{4}{|c|}{ March to May - 2020 vs $2018 / 2019$} & \multicolumn{4}{|c|}{ June to August - 2020 vs $2018 / 2019$} & \multicolumn{3}{|c|}{ September to November - 2020 vs } \\
\hline & $\begin{array}{l}\text { Pandemic } \\
\text { Mean } \\
\text { (SD) }\end{array}$ & $\begin{array}{l}\text { Prepandemic } \\
\text { Mean (SD) }\end{array}$ & $\begin{array}{l}\text { Percent } \\
\text { Change } \\
(\%)\end{array}$ & $\begin{array}{l}\mathrm{P} \text { - } \\
\text { value }\end{array}$ & $\begin{array}{l}\text { Pandemic } \\
\text { Mean } \\
\text { (SD) }\end{array}$ & $\begin{array}{l}\text { Prepandemic } \\
\text { Mean (SD) }\end{array}$ & $\begin{array}{l}\text { Percent } \\
\text { Change } \\
(\%)\end{array}$ & $\begin{array}{l}\mathrm{P} \text { - } \\
\text { value }\end{array}$ & $\begin{array}{l}\text { Pandemic } \\
\text { Mean } \\
\text { (SD) }\end{array}$ & $\begin{array}{l}\text { Prepandemic } \\
\text { Mean (SD) }\end{array}$ & $\begin{array}{l}\text { Perc } \\
\text { Cha| } \\
(\%)\end{array}$ \\
\hline Anal Cancer & $17(3.5)$ & $32.8(12.1)$ & -48.2 & 0.067 & $21.7(2.1)$ & $39.7(29.8)$ & -45.4 & 0.345 & $23.7(2.1)$ & $33.8(13.8)$ & -30 \\
\hline C Diff & $66(16.8)$ & $89.8(5.7)$ & -26.5 & 0.013 & $62.7(5.5)$ & $91.8(4.4)$ & -31.8 & $<0.001$ & $59.7(3.5)$ & $87(4.3)$ & -31.4 \\
\hline $\begin{array}{l}\text { Carcinoid } \\
\text { Tumor }\end{array}$ & $51(4.6)$ & $87(9.3)$ & -41.4 & $<0.001$ & $\begin{array}{l}61.3 \\
(12.1)\end{array}$ & $76.3(10.8)$ & -19.7 & 0.099 & $56.7(8.1)$ & $83.7(14.8)$ & -32. \\
\hline Celiac Disease & $67(7)$ & $90.3(3.6)$ & -25.8 & $<0.001$ & $68.7(3.8)$ & $88.5(3.3)$ & -22.4 & $<0.001$ & $71.3(2.3)$ & $88.2(3.3)$ & -19.1 \\
\hline Colitis & $73.3(6.7)$ & $88.8(4.7)$ & -17.4 & 0.004 & $87.7(4.2)$ & $92.2(3.7)$ & -4.9 & 0.139 & $86.7(4.9)$ & $87.2(4.8)$ & -0.6 \\
\hline Colon Cancer & $24.7(1.2)$ & $35.2(2.9)$ & -29.9 & 0.001 & $52(41.6)$ & $32.7(1.2)$ & 59.2 & 0.259 & $40.7(9.6)$ & $32.2(1.6)$ & 26.4 \\
\hline $\begin{array}{l}\text { Crohn's } \\
\text { Disease }\end{array}$ & $62.7(14)$ & $73(8.6)$ & -14.2 & 0.205 & $60.3(7.6)$ & $75.5(12.2)$ & -20.1 & 0.095 & $51(3)$ & $64.7(7.3)$ & -21 \\
\hline Diverticulitis & $69.7(4.2)$ & $91.3(3.9)$ & -23.7 & $<0.001$ & $82.7(2.3)$ & $92.7(4.1)$ & -10.8 & 0.006 & $84(3)$ & $85.8(5)$ & -2.1 \\
\hline Diverticulosis & $58.7(7.4)$ & $89.2(5.6)$ & -34.2 & $<0.001$ & $74(5.6)$ & $90.5(3.2)$ & -18.2 & 0.001 & $71(1)$ & $84.8(1.7)$ & $-16 .:$ \\
\hline Hemorrhoids & $75.3(9.8)$ & $88.3(9.5)$ & -14.7 & 0.097 & $84(6)$ & $82.3(7.9)$ & 2 & 0.761 & $87.7(0.6)$ & 77.5 (10.3) & 13.1 \\
\hline $\begin{array}{l}\text { Inflammatory } \\
\text { Bowel Disease }\end{array}$ & $63(9.2)$ & $75.8(10.1)$ & -16.9 & 0.107 & $69.3(5.1)$ & $69(10.1)$ & 0.5 & 0.96 & $71(9.2)$ & 79 (11.7) & -10 \\
\hline $\begin{array}{l}\text { Irritable Bowel } \\
\text { Syndrome }\end{array}$ & $78(8.5)$ & $89.5(4.7)$ & -12.8 & 0.031 & $84(2.6)$ & $87(3)$ & -3.4 & 0.184 & $82.3(6)$ & $86.3(5.4)$ & -4.6 \\
\hline Polyps & 60 (12.5) & $95.3(3.9)$ & -37.1 & $<0.001$ & $78.3(2.3)$ & $89.8(5.1)$ & -12.8 & 0.009 & $89.3(5.8)$ & $88.7(7.1)$ & 0.8 \\
\hline Rectal Cancer & $62(2.6)$ & $84.5(6.9)$ & -26.6 & 0.001 & $\begin{array}{l}79.3 \\
(18.3)\end{array}$ & $85.2(7.7)$ & -6.8 & 0.506 & $87(1.7)$ & $84.7(8.6)$ & 2.8 \\
\hline $\begin{array}{l}\text { Ulcerative } \\
\text { Colitis }\end{array}$ & $61.7(4.2)$ & $69(5)$ & -10.6 & 0.067 & $71(4.4)$ & $67.7(4.8)$ & 4.9 & 0.35 & $67(1.7)$ & $66(4)$ & 1.5 \\
\hline \multicolumn{12}{|l|}{$\begin{array}{l}\text { Symptom } \\
\text { Terms }\end{array}$} \\
\hline $\begin{array}{l}\text { Abdominal } \\
\text { Pain }\end{array}$ & $82.3(2.5)$ & $91.3(5.9)$ & -9.9 & 0.042 & $86(6.6)$ & $92.7(3.5)$ & -7.2 & 0.079 & $87.7(3.8)$ & $87.2(3.4)$ & 0.6 \\
\hline Constipation & $80.7(4)$ & $82(4)$ & -1.6 & 0.655 & $85.7(1.5)$ & $82.7(1.9)$ & 3.6 & 0.048 & $85.7(3.1)$ & $79(2.1)$ & 8.4 \\
\hline Diarrhea & $\begin{array}{l}80.7 \\
(14.4)\end{array}$ & 77 (3.2) & 4.8 & 0.544 & $84.3(5.9)$ & $81.3(2.9)$ & 3.7 & 0.32 & $73.7(2.5)$ & $71(2.9)$ & 3.8 \\
\hline Hematochezia & $\begin{array}{l}69.3 \\
(10.1)\end{array}$ & 79.7 (10.9) & -13 & 0.213 & $67.3(8)$ & $79.8(4.8)$ & -15.7 & 0.02 & $\begin{array}{l}74.7 \\
(13.7)\end{array}$ & $72(8.4)$ & 3.7 \\
\hline Melena & $66(3)$ & $80.7(6.5)$ & -18.2 & 0.008 & $65.3(8.1)$ & $73.5(6.4)$ & -11.1 & 0.141 & $77.7(6.5)$ & $74(4.1)$ & 5 \\
\hline Nausea & $85.7(5.5)$ & $83.3(2.7)$ & 2.8 & 0.402 & $92.3(4)$ & $85.5(2.1)$ & 8 & 0.01 & $84(1.7)$ & $81(1.7)$ & 3.7 \\
\hline Vomiting & $\begin{array}{l}77.7 \\
(11.9)\end{array}$ & $82.5(5.8)$ & -5.9 & 0.422 & $71.7(5.7)$ & $73.2(3.9)$ & -2.1 & 0.651 & $68(4)$ & $73.7(4.9)$ & -7.7 \\
\hline \multicolumn{12}{|l|}{$\begin{array}{l}\text { Procedure } \\
\text { Terms }\end{array}$} \\
\hline Anoscopy & $\begin{array}{l}47.7 \\
(19.9)\end{array}$ & $65.3(22.3)$ & -27 & 0.286 & 47 (8.2) & $67.3(18.7)$ & -30.2 & 0.123 & $62.3(3.8)$ & $66.5(8.6)$ & -6.3 \\
\hline $\begin{array}{l}\text { Capsule } \\
\text { Endoscopy }\end{array}$ & 44 (17.3) & 74.5 (15.2) & -40.9 & 0.029 & $74(25.1)$ & $68.7(13.3)$ & 7.8 & 0.679 & $71.7(12)$ & $68.5(20.8)$ & 4.6 \\
\hline Colectomy & $\begin{array}{l}57.3 \\
(10.3)\end{array}$ & $67.8(9.1)$ & -15.5 & 0.159 & $70.7(5.7)$ & $74.8(5.6)$ & -5.6 & 0.328 & $66(7.9)$ & 76.5 (12.1) & -13. \\
\hline Colonoscopy & $39(16)$ & $74.8(4.7)$ & -47.9 & 0.001 & $69.7(6.4)$ & $77.2(3)$ & -9.7 & 0.042 & $81(4.6)$ & $78(6.3)$ & 3.8 \\
\hline Endoscopy & $\begin{array}{l}55.7 \\
(14.6)\end{array}$ & $85(3.1)$ & -34.5 & 0.001 & $83.3(1.2)$ & $85.3(4.2)$ & -2.3 & 0.456 & $83.7(5.9)$ & $82.7(4.4)$ & 1.2 \\
\hline
\end{tabular}




\begin{tabular}{|c|c|c|c|c|c|c|c|c|c|c|c|}
\hline \multirow[b]{2}{*}{ Enteroscopy } & \multicolumn{4}{|c|}{ March to May - 2020 vs $2018 / 2019$} & \multicolumn{4}{|c|}{ June to August - 2020 vs $2018 / 2019$} & \multicolumn{3}{|c|}{ September to November - 2020 vs } \\
\hline & $47.7(17)$ & $57.8(24.3)$ & -17.6 & 0.542 & $\begin{array}{l}44.3 \\
(16.7)\end{array}$ & $59.7(8.1)$ & -25.7 & 0.096 & $61(11.8)$ & $59.5(9.3)$ & 2.5 \\
\hline Sigmoidoscopy & $\begin{array}{l}41.7 \\
(11.2)\end{array}$ & $80.2(12.1)$ & -48 & 0.003 & $48.7(8.7)$ & $73.7(15.1)$ & -33.9 & 0.036 & $82(12.5)$ & $74.5(15)$ & 10.1 \\
\hline
\end{tabular}

RSV for gastrointestinal search terms was identified using filters for the region, category, and date. The RSV search strategy that was used for this study was searching "USA" and "March 1, 2018, to August 31, 2021" and "All Categories."

In addition, the correlation between monthly RSV values were compared to the number of new monthly COVID-19 cases was assessed. New COVID-19 case numbers were extracted from the Johns Hopkins COVID-19 database (Coronavirus Resource Center 2021).

\section{Statistical Analyses}

Monthly American RSV data during the "pandemic period" (March 2020 to August 2021) were compared to mean monthly RSV data from the "pre-pandemic period" (March 2018-February 2020). The t-test of the two independent samples assuming unequal variances was utilized to compare the two groups in public interest during the seasons of the COVID-19 pandemic in America. A p-value $<0.05$ was established to be statistically significant in this study. All analyses were conducted on Microsoft Excel 2019. The presentation of statistical results was similar to a recent review (Misra 2021; Gupta 2021). Spearman's Rho correlation test was used to compare monthly RSV with new monthly COVID-19 cases.

\section{Results}

When analyzing the data, search terms were separated into disease, procedure, and symptom categories. Data from the COVID-19 pandemic was collected from March 2020 to August 2021. This period was divided into six seasons: 2020 Spring (March-May), 2020 Summer (June-August), 2020 Fall (September to November), Winter 2020 (December to February), 2021 Spring (March-May), and 2021 Summer (June-August). These RSV values were compared with RSV values from overlapping months between 2018-2020. Data and graphics of the internet search trends in gastrointestinal terms are shown in Table 1 and Figure 1.

\section{Disease terms (Table 1 and Figure 1)}

During Spring 2020, the disease search terms of Carcinoid Tumor, Polyps, Diverticulosis, Colon Cancer, Rectal Cancer, C Diff, Celiac, Disease, Diverticulitis, Colitis, Irritable Bowel Syndrome (10 out of 15 search terms) had a statistically significant $(p<0.05)$ decrease in RSV when compared to the pre-pandemic period (in order of descending percent change). In Summer 2020, there were also decreases in RSV, although this season only had 5 out of 15 with statistical significance, suggesting a subtle rebound in the public interest. This trend continues as the number of significant differences went from 5 terms (Fall 2020) to 4 terms (Winter 2020) to 3 terms (Spring 2021) to 0 terms (Summer 2021). This pattern correlates with the increased vaccine rollout period starting in Winter 2020. When comparing monthly disease RSV with new COVID-19 cases, there was no correlation among disease term RSV $(r s=-0.3065, p(2$-tailed $)=$ $0.21606)$.

When comparing the first year of the pandemic (March 2020 to February 2021) to the pre-pandemic period, 12 out of 15 disease search terms decreased in RSV. In the entirety of the study period (March 2020 to August 2021), 13 out of 15 disease search terms had a decrease in RSV.

Symptoms terms (Table 1 and Figure 1)

COVID-19's impact on symptom search terms was inconsistent between seasons. One possible explanation for this inconsistency is that some gastrointestinal symptoms overlap with COVID-19 symptoms. When comparing symptom RSV with COVID-19 cases, there was no correlation among symptom term RSV (rs = 0.12597, p (2-tailed) = 0.61844).

Procedure terms (Table 1 and Figure 1)

In Spring 2020, the procedure search terms of sigmoidoscopy, colonoscopy, capsule endoscopy, endoscopy (4 out of 7 search terms) had a statistically significant $(p<0.05)$ decrease in RSV when compared to the pre-pandemic data (in order of descending percent change). During Summer 2020, sigmoidoscopy and colonoscopy still had a relative decrease in RSV, which indicates a continued decrease in the public interest for these terms. For Fall 2020 and Spring 2021, COVID-19 cases were at their lowest. While only two terms (colonoscopy and endoscopy) had statistically increased, nearly all terms showed an increase to levels above pre-pandemic levels. This suggests that during this period, there was a surge in procedures these seasons due to a backlog of procedures.

Furthermore, there was a decrease in 6 out of 7 terms in the first year of the pandemic period (March 2020 to February 2021). When looking at the total study period (March 2020 to August 2021), only one procedure (sigmoidoscopy) had decreased RSV. When comparing procedure RSV with new COVID-19 cases, there was a strong negative correlation among procedure term RSV ( $\mathrm{ss}=-0.67596, \mathrm{p}(2$-tailed $)=0.00207)$.

\section{Discussion}


The declaration of the COVID-19 as a global pandemic by the WHO on March 11, 2020, has dramatically affected the public interest and access to medical services (Timeline of WHO's response to COVID-19 2020). The attention of the general population rapidly shifted as national lockdown orders were imposed, COVID-19 vaccines distributed, and seasonal variations in case numbers endured. This study set out to analyze internet search trends of specific gastroenterological diseases, symptoms, and procedures throughout the pandemic compared to pre-pandemic levels to determine how this event may influence public health and safety measures in the future.

Our study observed a reduction in the relative search volume of 10 of 15 gastrointestinal disease search terms during the early pandemic compared to previous years' data. Following this downtrend was a relative rebound to baseline during Fall 2020 with reductions in 5 of 15 search terms and only 3 terms by Spring 2021. The issuance of "stay at home" orders in the United States may explain the reductions in RSV when the public focus shifted away from gastroenterological health maintenance to the severe respiratory infection caused by COVID-19 infection (Coronavirus Guidelines for America 2020; KFF 2020). However, the lockdown measures proved necessary to reduce the transmission of COVID-19 by avoiding unnecessary patient traffic in hospitals and from hospitals to the community (Brindle 2020; COVID-surg Collaborative 2020).

Recent literature has cited similar trends in RSV across various medical specialties when comparing the initial phase of the pandemic to later seasons. For example, Esen-Salman et al. conducted a Google Trends analysis of public interest in dermatologic symptoms, conditions, treatments, and procedure search terms throughout the COVID-19 pandemic. Comparable to this study's findings, there was initially a marked decrease in the public interest, followed by a shift in RSV to levels prior to the pandemic (2021).

Of the 7 search terms related to gastrointestinal symptoms, the phrases "nausea," "diarrhea," and "constipation" displayed significant increases in search volume throughout the total study period. Certain gastrointestinal symptoms such as nausea and diarrhea appear prior to presentation with COVID-19 infection, which may explain this finding (Cholankeril 2020). Elucidation of COVID-19 symptomatology through Google Trends may be a valuable indication to screen for possible infection.

The Centers for Medicare and Medicaid Services imposed a temporary measure to "[delay] all elective surgeries, non-essential medical, surgical, and dental procedures" in response to the growing pandemic (Trump 2020; Centers for Medicare and Medicaid Services 2020; Goldman 2020). The postponement was an essential step to reduce the transmission of COVID-19 and ensure both patient and medical personnel safety (KFF 2020; Brindle 2020). Of note, in the Spring of 2020, procedural search terms in 4 of 7 key terms representing sigmoidoscopy, colonoscopy, capsule endoscopy, endoscopy decreased in internet search traffic compared to previous years. Although the reduction in procedures in many hospitals nationwide aided efforts to limit the viral spread, many hospitals and medical practices began operating under maximal capacity (Dhanda 2020).

The COVID-19 pandemic established severe barriers to access adequate care for many patients nationwide. In addition, the growing public fear of entering hospitals and healthcare facilities may have led to delayed diagnosis, progression of specific medical conditions, and decreased overall quality of life (ACS 2020). Khan et al. reported that COVID-19 patients with a pre-existing diagnosis of GI cancers had a significantly higher risk of hospitalization (RR 2.37 , $95 \%$ CI 2.19-2.55), mechanical ventilation (RR 2.16,95\% Cl 1.69-2.75), and mortality (RR 3.81, 95\% 3.14-4.63) compared to the control group (2021). Clinicians should take extra caution when delaying treatment and prioritize those with high-risk conditions to prevent worse outcomes in COVID-19 patients with pre-existing GI cancer and delayed access to care.

Mandeep S. Sawhney observed deferral of many gastrointestinal procedures in the early stages of the COVID-19 pandemic to a later period upon formalizing guidelines with more significant safety measures (Sawhney 2020). Many healthcare institutions adapted to the pandemic by implementing new visitation policies, regular COVID testing, proper allocation PPE, along with social distancing to limit the spread of the virus per national recommendations (Francescani 2020). During the Fall 2020 and Spring 2021, COVID-19 cases were at their lowest due to the lifting of lockdown measures and vaccine rollouts available to the healthcare workers and the public. These events led to progressive increases in elective surgeries to meet the growing demand for those treated earlier in the pandemic (Moletta 2020). With the drop in case numbers, there was a significant rebound of two RSV terms, colonoscopy and procedure RSV to near baseline nearly all terms rose above pre-pandemic levels.

Due to the backlog of procedures, multiple medical specialties observed increased workload upon lifting lockdown restrictions and returning to pre-pandemic life. Bhambavani et al. observed a rebound of procedural capacity in May 2021 among all urological procedure categories except male infertility (2020). Similar reports indicate a growing interest in non-essential cosmetic facial plastic surgery in the face of the ongoing pandemic (Dhanda 2020). A single-center prospective cohort study conducted by Dawod et al. indicated that endoscopy procedures with appropriate PPE and preoperative testing are associated with a low risk of periprocedural COVID-19 infection for outpatients and endoscopy unit staff (2021). Proper implementation of infection prevention measures, and increased vaccination efforts, may pave the way for the regular utility of healthcare services.

The COVID-19 pandemic decreased the outreach physicians have in education and guidance for their patients, which may have resulted in decreased RSV compared to previous years. In the field of otolaryngology, there was roughly an $80 \%$ reduction in the number of completed appointments from mid-March 2020 to mid-April 2020 compared with the corresponding period in 2019 (Kasle 2020). Furthermore, emergency department consultations for ENT related concerns were reduced by nearly $80 \%$ over the course of the pandemic (Shipchandler 2020). To combat the lack of access to medical services, healthcare providers have responded by providing care through telemedicine (Rodriguez 2021). Outpatient visits in GI clinics via telemedicine may serve to reduce exposure to COVID-19 and remove barriers to care for many patients (Keesara 2020).

The COVID-19 pandemic has severely impacted the lifestyle and health of the US population at large. Opportunities for physical activity were limited during the lockdown upon the closure of many gyms, workplaces, and public spaces. During the COVID-19 pandemic, the overall step counts rapidly decreased worldwide (Keesara 2020). As a result, sedentary lifestyles and unhealthy dietary habits became routine for many. An inability to work or exercise, replaced by increased sugar and alcohol intake, may escalate stress and anxiety levels and worsen existing mental health issues (World Health Organization 2020; Foulds 
2015; Tison 2020; Mattioli 2020). Nielsen reported a 54\% increase in national sales of alcohol for the week ending March 21, 2020, compared with one year before (The Nielsen Company 2020). Furthermore, increased alcohol use is linked to many gastrointestinal conditions such as esophageal squamous cell cancer, gastric cancer, hepatocellular carcinoma, and colorectal cancer (Scherübl 2020). Increased alcohol intake and exaggerated stress response may worsen several functional GI disorders via pathways of the gut-brain axis (Gubatan 2021). It is imperative that physicians take into account lifestyle disturbances caused by COVID-19 to optimize the delivery of high-quality health care.

\section{Limitations}

Although this study has shown a decrease in Google Trends search interest in gastrointestinal topics with subsequent elevations in later periods, there is no evidence to suggest that this could directly impact health outcomes. Another limitation is that internet searches were analyzed via English, whereas many internet searches may have been in a different language. Additionally, only one search engine was used. However, the Google search engine has approximately $90 \%$ of the internet market share (StatCounter Global Stats), so it likely represents all internet searches. This study was further limited by the geographical variance in the institution of local lockdown measures and vaccination distribution efforts.

\section{Conclusions}

This is the first study to analyze the trends of public interest in gastrointestinal search terms affected by the COVID-19 pandemic over the first six seasons from March 1, 2018, to August 31, 2021. Despite the initial decline of public interest in gastrointestinal RSV, there was an observed a resurgence in interest that may exceed that of pre-pandemic levels. Physicians should be aware of the societal changes in understanding gastrointestinal health over the pandemic. COVID-19 allowed for more significant opportunities for health professionals to provide care via telemedicine and reach patients requiring essential medical information and guidance. Google trends have become a valuable tool to recognize changes in public search interest of medical information and guide patient care and management during future outbreaks.

\section{Declarations}

Ethics approval and consent to participate: Not applicable.

Consent for publication: Not applicable.

Availability of data and materials: Data are available from corresponding authors upon a reasonable request.

Competing interests: The authors declare that they have no competing interests regarding this manuscript.

Funding: The authors received no financial support or grants for this article's research, authorship, and publication.

Authors' contributions: MY, HP, RR, OB, AK, SS contributed to data curation, formal analysis, and original manuscript drafting, MY, HP, RR, OB, AK, SS contributed to conceptualization, investigation, methodology, and manuscript review and editing. All authors, MY, HP, RR, OB, AK, SS approved the final draft submitted.

Acknowledgments: None.

\section{References}

1. ACS, Guidelines for Triage and Management of Elective Cancer Surgery Cases during the Acute and Recovery Phases of Coronavirus Disease 2019 (COVID-19) Pandemic, (2020)

https://www.facs.org//media/files/covid19/acs_triage_and_management_elective_cancer_surgery_during_acute_and_recovery_phases.ashx accessed 25 April 2020.

2. Becerra-García JA, Sánchez-Gutiérrez T, Barbeito S, Calvo A (2021) COVID-19 pandemic and mental health in Spain: An analysis of their relationship using Google Trends. Rev Psiquiatr Salud Ment. doi: 10.1016/j.rpsm.2021.05.001.

3. Bhambhvani, H. P., Tijerina, J. D., Parham, M. J., Greenberg, D. R., \& Eisenberg, M. L. (2020). Public interest in elective urological procedures in the COVID19 pandemic: A google trends analysis. Urology Practice, 7(6), 496-501. https://doi.org/10.1097/upj.0000000000000179

4. Brindle M, Ariadne, B. Health, H. Th, Managing COVID-19 in Surgical Systems, Ann. Surg, 2020, https://doi.org/10.1097/SLA.0000000000003923.

5. Centers for Medicare and Medicaid Services: CMS Releases Recommendations on Adult Elective Surgeries, Non-Essential Medical, Surgical, and Dental Procedures during COVID-19 response. 2020. Available at https://www.cms.gov/newsroom/ press-releases/cms-releases-recommendations-adultelective-surgeries-non-essential-medical-surgical-and-dental. Accessed July 24, 2020.

6. Cholankeril, G., Podboy, A., Aivaliotis, V. I., Tarlow, B., Pham, E. A., Spencer, S. P., Kim, D., Hsing, A., \& Ahmed, A. (2020). High prevalence of concurrent gastrointestinal manifestations in patients with severe acute respiratory syndrome coronavirus 2: Early experience from California. Gastroenterology, 159(2), 775-777. https://doi.org/10.1053/j.gastro.2020.04.008

7. Coronavirus Guidelines for America. The White House. The White House. https:// www.whitehouse.gov/briefings-statements/coronavirus-guidelinesamerica/, Accessed date: 23 May 2020.

8. Coronavirus Resource Center. 2021. https://coronavirus.jhu.edu/ 
9. COVID-surg Collaborative, Global Guidance for Surgical Care during the COVID-19 Pandemic, BJS, 2020, https://doi.org/10.1002/bjs.11646.

10. Dawod, S. M., Dawod, Q. M., Hajifathalian, K., Sampath, K., Mahadev, S., Carr-Locke, D. L., \& Sharaiha, R. Z. (2021). 111 risk of CoVID-19 infection to both patients and endoscopy unit staff following endoscopy: A single-center prospective Cohort Study. Gastroenterology, 160(6).

https://doi.org/10.1016/s0016-5085(21)00814-3

11. Dhanda, A. K., Leverant, E., Leshchuk, K., \& Paskhover, B. (2020). A google trends analysis of facial plastic surgery interest during the COVID-19 pandemic. Aesthetic Plastic Surgery, 44(4), 1378-1380. https://doi.org/10.1007/s00266-020-01903-y

12. Esen-Salman K, Akın-Çakııı Ö, Kardeş S, Salman A (2021) Public interest in dermatologic symptoms, conditions, treatments, and procedures during the COVID-19 pandemic: Insights from Google Trends. Dermatol Ther 34:e14895. doi: 10.1111/dth.14895.

13. Eysenbach G (2006) Infodemiology: tracking flu-related searches on the web for syndromic surveillance. AMIA Annu Symp Proc 2006:244-8

14. Foulds JA, Adamson SJ, Boden JM, Williman JA, Mulder RT. Depression in patients with alcohol use disorders: systematic review and meta-analysis of outcomes for independent and substance-induced disorders. J Affect Disord. 2015;185:47-59. doi:10.1016/j.jad.2015.06.024

15. Francescani, C. Timeline: The first 100 days of New York Gov. Andrew Cuomo's COVID-19 response - ABC News. Accessed July 19, 2020. https:// abcnews.go.com/US/News/timeline-100-days-york-gov-andrew- cuomos-covid/story?id=71292880

16. Goldman HB and Haber GP: Recommendations for tiered stratification of urological surgery urgency in the COVID-19 era. J Urol $2020 ; 204: 11$.

17. Gubatan, J., Zikos, T., Spear Bishop, E., Wu, J., Gottfried, A., Becker, L., Habtezion, A., \& Neshatian, L. (2021). Gastrointestinal symptoms and healthcare utilization have increased among patients with functional gastrointestinal and motility disorders during the Covid-19 pandemic. Neurogastroenterology \& Motility. https://doi.org/10.1111/nmo.14243

18. Güdük M, Orhun Ö, Dursun AT, Küçüksüleymanoğlu D, Deniz Z, Usseli MI, Bozkurt B, Kardeş S, Ekşi MŞ (2021) Impact of COVID-19 on interest in pediatric neurosurgery related symptoms, diseases, and treatments. J Neurosurg Sci. doi: 10.23736/S0390-5616.21.05416-3.

19. Gupta R, Pakhchanian H, Raiker R, Asahi M, Raparla N, Belyea D. Public Interest in Refractive Diseases and Treatments During the COVID-19 Pandemic: A Google Trends Analysis. Cureus. 2021 Aug 15;13(8):e17207. doi: 10.7759/cureus.17207. PMID: 34540434; PMCID: PMC8442795.

20. Kardeş S, Erdem A, Gürdal H (2021) Public interest in musculoskeletal symptoms and disorders during the COVID-19 pandemic: Infodemiology study. Z Rheumatol. doi: 10.1007/s00393-021-00989-2.

21. Kasle DA, Torabi SJ, Savoca EL, Judson BL, Manes RP. Outpatient otolaryngology in the era of COVID-19: a data-driven analysis of practice patterns. Otolaryngol Head Neck Surg 2020. https://doi.org/10.1177/0194599820928987. May.

22. Keesara S, Jonas A, Schulman K. Covid-19 and health care's digital revolution. N Engl J Med 2020. https://doi.org/10.1056/NEJMp2005835. April.

23. KFF. When state stay-at-home orders due to coronavirus went into effect. https:// www.kff.org/other/slide/when-state-stay-at-home-orders-due-tocoronavirus-went- into-effect/; April 9, 2020, Accessed date: 23 May 2020.

24. Khan, A., Bilal, M., Morrow, V. R., Annie, F., Mansoor, E., Cooper, G. S., Hutson, W. R., Thakkar, S., \& Singh, S. (2021). 112 impact of COVID-19 infection among patients with pre-existing gastrointestinal cancers in the United States: A Multicenter Research Network Study. Gastroenterology, 160(6). https://doi.org/10.1016/s0016-5085(21)00815-5

25. Kutlu Ö (2020) Analysis of dermatologic conditions in Turkey and Italy by using Google Trends analysis in the era of the COVID-19 pandemic. Dermatol Ther 33:e13949. doi: 10.1111/dth.13949.

26. Mattioli AV, Sciomer S, Cocchi C, Maffei S, Gallina S. Quarantine during COVID-19 outbreak: changes in diet and physical activity increase the risk of cardiovascular disease. Nutr Metab Cardiovasc Dis. (2020) 30:1409-17. doi: 10.1016/j.numecd.2020.05.020

27. Misra DP, Zimba O, Gasparyan AY (2021) Statistical data presentation: a primer for rheumatology researchers. Rheumatol Int 41:43-55. doi: 10. 1007/ s00296- 020-04740-z

28. Moletta, L.,vPierobon, E. S., Capovilla, G., Costantini, M., Salvador, R., Merigliano, S., \& Valmasoni, M.(2020). International guidelines and recommendations for surgery during covid-19 pandemic: A systematic review. International Journal of Surgery, 79, 180-188. https://doi.org/10.1016/j.jisu.2020.05.061

29. Pakhchanian H, Raiker R, Kardeş S, Bilal M, Alam K, Khan A, Hutson W, Thakkar S, Singh S. Impact of CoVID-19 on interest in hepato-pancreato-biliary diseases. Environ Sci Pollut Res Int. 2021 Aug 23:1-6. doi: 10.1007/s11356-021-16063-y. Epub ahead of print. PMID: 34424472; PMCID: PMC8381708.

30. Rodriguez, N. J., Okwara, N. C., Shen, L., Jajoo, K., \& Chan, W. W. (2021). 114 telemedicine in the COVID-19 ERA: Impact on disparities in access to ambulatory care.

31. Sawhney MS, Bilal M, Pohl H, Kushnir VM, Khashab MA, Schulman AR, Berzin TM, Chahal P, Muthusamy VR, Varadarajulu S, Banerjee S, Ginsberg GG, Raju GS, Feuerstein JD (2020) Triaging advanced GI endoscopy procedures during the COVID-19 pandemic: consensus recommendations using the Delphi method. Gastrointest Endosc 92:535-542. doi: 10.1016/j.gie.2020.05.014.

32. Scherübl, H. (2020). Alcohol use and gastrointestinal cancer risk. Visceral Medicine, 36(3), 175-181. https://doi.org/10.1159/000507232

33. Shipchandler TZ, Nesemeier BR, Parker NP, et al. Telehealth opportunities for the otolaryngologist: a silver lining during the COVID-19 pandemic. Otolaryngol Head Neck Surg 2020. https://doi.org/10.1177/0194599820929641. May.

34. StatCounter Global Stats, "Browser, OS, Search Engine Including Mobile Usage Share." https://gs.statcounter.com/.

35. The Nielsen Company. Rebalancing the 'COVID-19 Effect on alcohol sales. Published May 7,2020 . Accessed August $27,2020$. https://www.nielsen.com/us/en/insights/article/2020/rebalancing-the-covid-19-effect-on- alcohol-sales/

36. Timeline of WHO's response to COVID-19. Accessed July 19, 2020. https://www.who.int/news-room/detail/29-06-2020- covidtimeline 
37. Tison, G. H., Avram, R., Kuhar, P., Abreau, S., Marcus, G. M., Pletcher, M. J., \& Olgin, J. E. (2020). Worldwide effect of covid-19 on physical activity: A descriptive study. Annals of Internal Medicine, 173(9), 767-770. https://doi.org/10.7326/m20-2665

38. Trump DJ: Proclamation on declaring a national emergency concerning the novel coronavirus disease (COVID-19) outbreak. 2020. Available at https://www.whitehouse.gov/presidential- actions/proclamation-declaring-national-emergency-concerning- novel-coronavirus-disease-covid-19-outbreak/. Accessed May 18, 2020.

39. World Health Organization. Alcohol does not protect against COVID-19; access should be restricted during lockdown. Published April 14, 2020. Accessed August 27, 2020. https://www.euro.who.int/en/health-topics/disease- prevention/alcohol-use/news/news/2020/04/alcohol-does-not-protect-againstcovid-19-access-should- be-restricted-during-lockdown

\section{Figures}

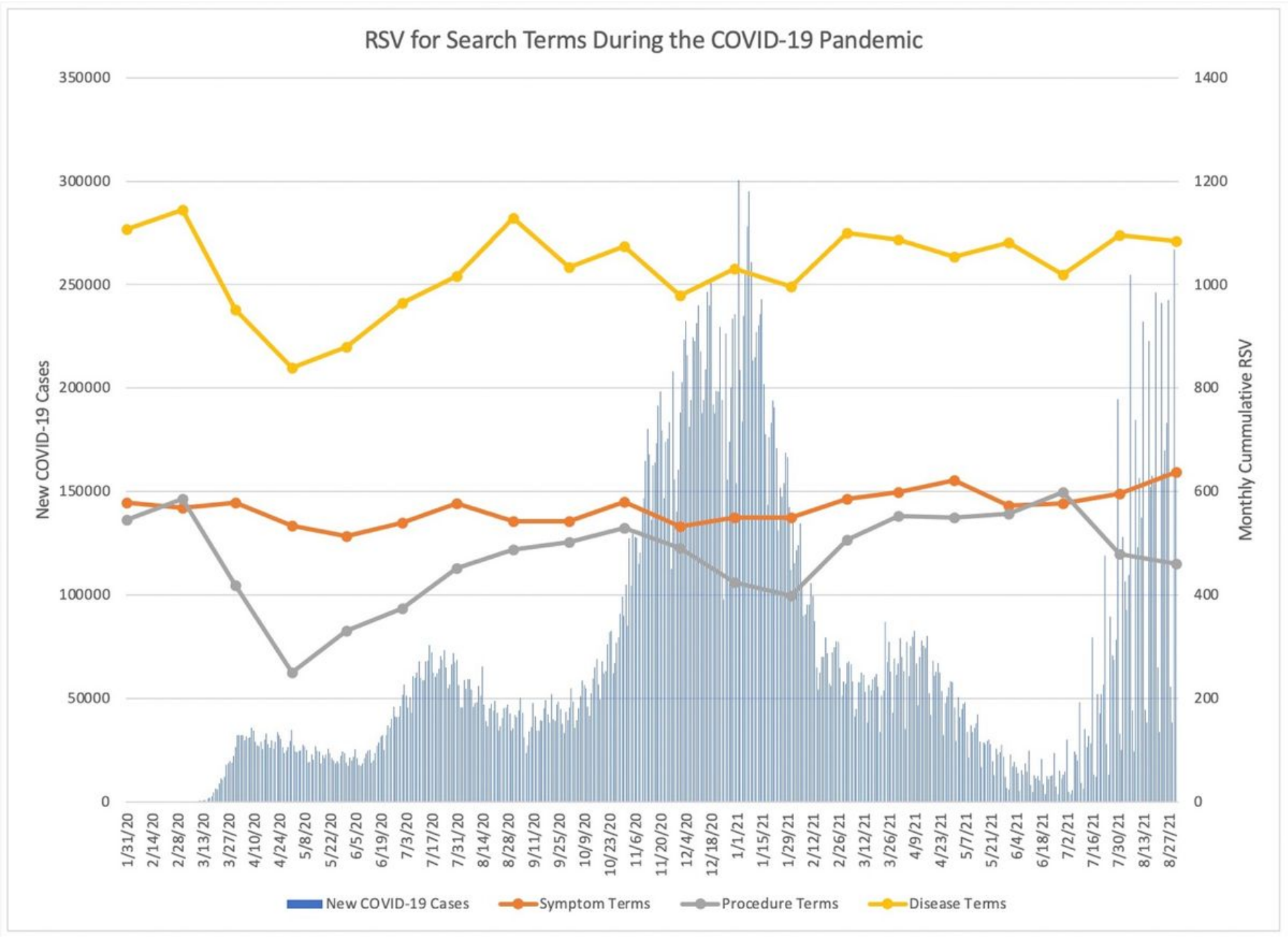

\section{Figure 1}

Gastrointestinal Google search volumes during the COVID-19 pandemic compared with new COVID-19 cases

Monthly cumulative Relative search volumes (RSV) were assessed between January 2020 and August 2021 to symptoms, procedures, and disease terms. These RSV are graphed on a plot of new COVID-19 cases. 